\title{
O SISTEMA CAPITALISTA E SUAS CRISES CÍCLICAS: DO RETROCESSO SOCIAL À ESCRAVID AOO CONTEMPORÂNEA
}

\section{CAPITALISMANDITS CICLICAL CRYSIS:FROMSOCIAL SETBACK TO CONTEMPORARY SLAVERY \\ EL SISTEMA CAPITALISTA Y SUS CRISIS CÍCLICAS: DEL RETROCESO SOCIAL A LA ESCLAVITUD CONTEMPORÁNEA}

Isabele Bandeira de Moraes D’Angelo'

Licença CC BY:

Artigo distribuído sob os termos Creative Commons, permite uso e distribuição irrestrita em qualquer meio desde que o autor credite a fonte original.

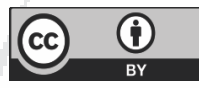

\section{Lília Carvalho Finelli²}

Resumen: O capitalismo tem fases cíclicas, nas quais se refaz e, no processo, atinge os trabalhadores, que apenas possuem sua força de trabalho. O presente artigo tem como objetivo geral questionar a relação possível entre os apelos ao retrocesso social para salvar a economia, aqui tratados por meio da metodologia de análise dos dispositivos principais que alteraram a legislação brasileira no ano de 2017, em especial a regulamentação da terceirização e a Reforma Trabalhista, mostrando o estado da arte atual do ordenamento jurídico. No que se refere à Reforma, foram escolhidos três aspectos alterados que se relacionam diretamente ao combate ao trabalho escravo contemporâneo, quais sejam, a modificação do conceito de grupo empresarial, a possibilidade de aplicação de fontes comuns do Direito na análise de casos trabalhistas sem a observância dos princípios deste ramo e o tabelamento do dano extrapatrimonial vinculado ao salário contratual obreiro. Além do breve exame dos dispositivos, com base no referencial teórico principal de Everaldo Gaspar Lopes de Andrade, passou-se, ainda, à vinculação dos temas com o "Dumping Social", demonstrando, como conclusão, a face real do ressurgimento cíclico do capitalismo, representado pela Fênix, com o objetivo geral de demonstrar a utilização do trabalho escravo contemporâneo como base do sistema e seu sustentáculo em tempos de "crise".

1 Doutora e Mestra em Direito pela Universidade Federal de Pernambuco - UFPE. Pós-Doutoranda pela Universidade do Porto/PT. Professora Adjunta da Universidade de Pernambuco - UPE e Professora permanente do PPGDH/ UFPE. Coordenadora Setorial de Extensão e Cultura da FCAP-UPE. Membro da Academia Pernambucana de Direito do Trabalho. Membro da Associação Luso Brasileira de Juristas do Trabalho - JUTRA. Líder do Grupo de Pesquisa Direito do trabalho e os dilemas da sociedade contemporânea. Membro do GPTEC - Grupo de Pesquisa Trabalho Escravo Contemporâneo. E-mail: belebm@hotmail.com. Orcid id: http://orcid.org/0000-0001-9592-6049. Currículo Lattes: http://lattes.cnpq.br/3491163418088431

2 Doutoranda, Mestra e bacharela em Direito pela Faculdade de Direito da UFMG. Professora Universitária. Advogada. E-mail: lilia.finelli@gmail.com 
Palavras-chave: Direito do Trabalho; Reforma Trabalhista; Vedação ao retrocesso; Terceirização.

Abstract: Capitalism has cyclical phases in which it is remade and, in the process, affects workers, who only have their labor. The general objective of this article is to question the possible relationship between the calls for social retrogression to save the economy, addressed here through an analysis of the main provisions that changed the Brazilian legislation in 2017, particularly the regulation of outsourcing and the Labor Reform, showing the current state-of-the-art in the legal system. With regard to the Reform, three altered aspects were chosen that are directly related to the fight against contemporary slave labor, namely, the changes to the concept of business group; the possibility of applying common sources of law in the analysis of labor cases without the observance of the principles of this branch; and the tabulation of off-balance sheet damages linked to the contractual wage for workers. In addition to a brief examination of the devices, based on the main theoretical framework of Everaldo Gaspar Lopes de Andrade, the themes were also linked to "Social Dumping". In conclusion, this work demonstrates the real face of the cyclical resurgence of capitalism, represented by Fênix, in order to demonstrate the use of contemporary slave labor as the basis of the system and its support in times of "crisis".

Keywords: Labor law; Labor reform; Backward fence; Outsourcing.

Resumen: El capitalismo tiene fases cíclicas, en las cuales se refaz y, en el proceso, alcanza a los trabajadores, que apenas poseen su fuerza de trabajo. El presente artículo tiene como objetivo general cuestionar la relación posible entre los apelos al retroceso social para salvar la economía, aqui tratados por medio de la metodología de análisis de los dispositivos principales que alteraron la legislación brasileña en el año 2017, en especial la reglamentación de la tercerización y la Reforma Laboral, mostrando el estado del arte actual del ordenamiento jurídico. En lo que se refiere a la Reforma, fueron elegidos tres aspectos alterados que se relacionan directamente al combate del trabajo esclavo contemporáneo, cuales sean, la modificación del concepto de grupo empresarial, la posibilidad de aplicación de fuentes comunes del Derecho en el análisis de casos laborables sin la observancia de los principios de este ramo y el escandallo del daño extrapatrimonial relacionado al salario contractual obrero. Además del breve examen de los dispositivos, con base en el referencial teórico principal de Everaldo Gaspar Lopes de Andrade, se pasó, todavía, a la vinculación de los temas con el "Dumping Social", demostrando, como conclusión, la cara real del resurgimiento cíclico del capitalismo, representado por el Fênix, con el objetivo general de demostrar la utilización del trabajo esclavo contemporáneo como base del sistema y su sustentáculo en tiempos de "crisis".

Palabras clave: Derecho del Trabajo; Reforma Laboral; Prohibición al retroceso; Tercerización.

\section{INTRODUÇÃO}

Ao estudar a História, percebe-se que todos os modos de produção que existiram surgiram, se desenvolveram, atingiram seu apogeu e entraram em decadência. Tudo isso em um tempo histórico razoável. Diversas são as crises que assolam o universo do trabalho humano, o sistema capitalista, advento do liberalismo, em seus quase 200 anos, e o movimento frenético da globalização deixaram de repercutir nos espaços meramente locais, passando a atingir os trabalhadores em dimensão internacional. 
O mundo nunca produziu tanta riqueza, mas também nunca houve tanta miséria e tantas crises cíclicas. Pode-se dizer que as crises sucessivas fazem parte da essência do capitalismo e o motivo, segundo Marx e Engels, é "civilização em excesso, meios de subsistência em excesso, indústria em excesso, comércio em excesso"3. As forças produtivas, apenas, não são suficientes para manter sua civilização, pois essas mesmas forças se tornam fortes demais e acabam sendo extravasadas, o que leva a sociedade a cair no caos e na desordem, colocando em risco a manutenção da sua própria existência. Nas palavras dos mesmos autores, "as relações burguesas tornaram-se estreitas demais para conterem a riqueza que produziram"4.

Assim, há apenas duas formas para a burguesia superar as crises; uma passa pelo aniquilamento forçado de um enorme contingente de forças produtivas - o que se costuma chamar "reestruturação produtiva"; e a outra pela conquista de novos mercados sem deixar de explorar os mais antigos, o que costuma fazer a partir do "Dumping Social". As autoras do presente artigo entendem que, para melhor compreensão do momento atual e todo o discurso de "deve-se fazer sacrifícios para salvar a economia" que deixa os menos atentos e incautos atordoados, passa-se pelo saber necessário do modus operandi do sistema capitalista de produção que se retroalimenta a partir de crises recorrentes, a partir das quais ressurge tal qual "fênix". E esse ressurgimento envolve a utilização de práticas como o trabalho escravo contemporâneo.

No passado, o aparecimento das gigantes multinacionais e o seu poderio econômico, em face de diversas nações, fez com que a mão-de-obra se deslocasse de um local a outro, assim como ensejou a transferência de todo o meio de produção, de um país para outro, de acordo com melhores condições econômicas, sociais e legislativas para as empregadoras. A tal fenômeno alguns autores atribuem o nome de "movimento pendular do capitalismo".

Tantas mudanças estruturais constantes e pulverizadoras fizeram com que a atuação reivindicatória e revolucionária dos obreiros se tornasse cada vez menos eficaz, na medida em que agora se exige uma luta a ser desencadeada nos planos locais, regionais e supranacionais. E essa luta também é real nos casos envolvendo a escravização que atinge a liberdade e a dignidade dos trabalhadores.

As metamorfoses que vêm ocorrendo do mundo do trabalho desencadearam uma crise sem precedentes nas relações individuais, a ponto de o professor Everaldo Gaspar Lopes de Andrade em sua famosa trilogia, problematizar, refutar e propor epistemologicamente o deslocamento do

3 PRAUN, Luci. Reestruturação produtiva, saúde e degradação do trabalho. Campinas: Papel Social, 2016. p. 34.

4 PRAUN, Luci. Reestruturação produtiva, saúde e degradação do trabalho. Campinas: Papel Social, 2016. p. 34.

5 Entre a vasta produção do Prof. Dr. Everaldo Gaspar, destacam-se as três obras pertencentes à sua trilogia, na qual promove uma verdadeira revolução nos postulados tradicionais do Direito do Trabalho: ANDRADE, Everaldo Gaspar Lopes de. O Direito do Trabalho na Filosofia e na Teoria Social Crítica. Os Sentidos do trabalho subordinado na cultura e no poder das organizações. São Paulo: LTr, 2014. Princípios de Direito do Trabalho. Fundamentos Teórico Filosóficos. São Paulo: LTr, 2008 e Direito do Trabalho e Pós-modernidade. Fundamentos para uma teoria geral. São Paulo: LTr, 2005. 
próprio objeto do Direito do Trabalho - do trabalho contraditoriamente livre/subordinado para todas as possibilidades e alternativas de trabalho e rendas compatíveis com a dignidade humana. Suas propostas teóricas têm provocado uma nova pauta hermenêutica e novos fundamentos teóricofilosóficos para a formulação de novos fundamentos, sobretudo nos dois troncos fundamentais deste ramo do conhecimento jurídico - o Direito Individual do Trabalho e o Direito Sindical, considerando ainda suas repercussões no Direito Internacional do Trabalho.

A obra reestruturação produtiva, saúde e degradação do trabalho, de Luci Praun aborda exatamente este universo cotidiano de superexploração e precariedade subjetiva, em suas palavras:

O ambiente de trabalho resultante dessas estratégias é sem dúvidas paradoxal: nele os trabalhadores transitam entre as incertezas do mercado e a insistente campanha sobre a necessidade do engajamento como saída para manter-se empregado; entre o reconhecimento de uma realidade aparentemente exterior, perpassada pelas mais diversas formas de precarização do trabalho, e o discurso de valorização de suas potencialidades, cotidianamente propagado no ambiente de trabalho. O que tem resultado desse processo é um ambiente marcado pela competição, individualização e solidão. ${ }^{6}$

Ao analisarem a crise a partir da obra "O Capital" de Karl Marx, Hector Benoit e Jadir Antunes ${ }^{7}$ asseveram que o capitalismo segue com a dialeticidade de diversas contradições frutos do próprio sistema. Tais contradições seguem desde a produção básica de mercadorias, da produção de maisvalia, até a forma de circulação do capital e da acumulação de lucro. Não convém a este trabalho a análise das contradições do capitalismo, mas sim, o entendimento de que tais contradições, são intrinsecamente ligadas ao sistema, isto é, o capitalismo, produz suas próprias crises. Toda vez que o modo de produção não mais viabilizar o acúmulo rápido riqueza nem gerar lucro fácil, haverá a possibilidade de uma crise no sistema. Segundo Hector Benoit e Jadir Antunes:

Uma vez que o lucro e a taxa geral de lucro são a mola propulsora do capital, cada vez que eles caírem, cairá junto a acumulação capitalista. A paralisia da produção provocada por uma queda na taxa geral de lucro mostrará a toda a sociedade capitalista, sem disfarces, já que o próprio capitalista prático admite parar a produção toda vez que ela não Ihe fornecer o lucro médio esperado, que o capitalista prático tem por meta unicamente abocanhar para si a maior fatia de mais-valia já produzida e realizada. Toda vez que esta fatia abocanhada diminuir de tamanho em relação ao volume do capital empregado, o capitalista prático, este que se orgulha de encontrar no lucro uma justificativa moral para seu enriquecimento privado, não se envergonhará de retrair a produção e lançar toda a sociedade na crise e na depressão. ${ }^{8}$

$6 \quad$ PRAUN, Luci. Reestruturação produtiva, saúde e degradação do trabalho. Campinas: Papel Social, 2016. p. 11.

7 BENOIT, Hector; ANTUNES, Jadir. O problema da crise capitalista em o capital de Marx. Jundiai: Paco Editorial, 2016.

8 BENOIT, Hector; ANTUNES, Jadir. O problema da crise capitalista em o capital de Marx. Jundiai: Paco Editorial, 2016. p. 165. 
A redução da produção e o desencadear de uma crise amplia as desigualdades sociais, tendo em vista que os mais afetados são os pequenos capitais, que são obrigados a se entregarem a capitalistas maiores ou, até mesmo, a saírem do mercado.

Com a crise, a ruína do pequeno proprietário e o processo de fusão entre diferentes capitais individuais que lutam desesperadamente para não serem devorados pelos capitais maiores, seriam, então, aprofundados. A crise produziria, assim, uma ampliação cada vez maior do tamanho médio da propriedade industrial capitalista e sua conversão em propriedade monopolista. ${ }^{9}$

A crise também afeta diretamente e de modo fulminante a vida da classe trabalhadora, já que com a diminuição da produtividade, sua força de trabalho vai se tornando desnecessária, e a sua manutenção, um peso para o empregador. Assim, para alguns políticos e legisladores, em nome do crescimento econômico, é necessário "atualizar" o Direito do Trabalho a serviço dos interesses do capital, e o abrandamento do tipo penal que trata sobre a utilização do trabalho análogo ao de escravo é exemplo disso.

O trabalhador, por sua vez, para não se ver completamente desamparado, é forçado a aceitar a supressão de seus direitos, pois, afinal, para o trabalhador dentro de um modo de vida capitalista, nada pode ser pior do que o desemprego. Neste sentido, mais uma vez Hector Benoit e Jadir Antunes:

A pressão deste exército industrial excedente obrigaria a massa de trabalhadores que ainda permanece empregada a aceitar as imposições do capital, a aceitar jornadas de trabalho mais longas ou mais intensas e extenuantes, a aceitar um rebaixamento de salários, seja direto ou indireto, a trabalhar em condições mais insalubres, em condições, portanto, menos dispendiosas em capital constante e a trabalhar em turnos alternados. ${ }^{10}$

Assim, o sistema capitalista se utiliza do próprio poder político do Estado para estabelecer suas diretrizes e se manter hegemônico, ou seja, os poderes políticos dos governos passam a servir ao capital, sob pena de falência do próprio sistema. Para Zygmunt Bauman e Carlo Bordoni, "o neoliberalismo se instala no próprio Estado"11.

A sociedade em que vivemos tem seus alicerces forjados no crescimento econômico, cujas bases são a acumulação ilimitada. ${ }^{12}$ De modo que as demandas por produção e consumo são fundamentais, todas as vezes que esta regra for quebrada, as crises serão geradas.

9 BENOIT, Hector; ANTUNES, Jadir. O problema da crise capitalista em o capital de Marx. Jundiai: Paco Editorial, 2016. p. 186.

10 BENOIT, Hector; ANTUNES, Jadir. O problema da crise capitalista em o capital de Marx. Jundiai: Paco Editorial, 2016. p. 187.

11 BAUMAN, Zygmunt; BORDONI, Carlo. Estado de Crise. Tradução Renato Aguiar. Rio de Janeiro: Jorge Zahar, 2016. p. 28.

12 D'ANGELO, Isabele Bandeira de Moraes; RABÊLO, Rebeka Yasmim Teotônio Pereira. Desvendando a flexibilização no direito do trabalho como solução para a crise econômica brasileira: o que os noticiários não contam. Revista Jurídica Unicuritiba, Curitiba, v. 04, n. 53, p. 275-305, 2018. 
Em sociedades globais, as crises afetam diversos países e possuem causas e consequências quem estão acima do alcance dos governos locais, ou seja, os problemas e as crises são globais, mas são os Estados nacionais que lidam com seus efeitos. Assim, o estado perde a capacidade de tomar as suas próprias decisões políticas, se rendendo aos fluxos globais dos mercados, e direcionando as suas políticas públicas e econômicas para atender aos interesses do capital.

O Estado foi expropriado de uma parcela grande e crescente de seu antigo poder imputado e genuíno (de levar as coisas a cabo), o qual foi capturado por forças supraestatais (globais) que operam num "espaço de fluxos" (termo de Manuel Castells) politicamente incontrolável- haja vista o alcance das agências políticas sobreviventes não ter progredido além das fronteiras do Estado. ${ }^{13}$

Neste contexto, a supressão de direitos trabalhistas, em nome da modernização e da retomada do crescimento econômico se enquadram como tentativas de se impor, por meio de políticas legislativas, os interesses do mercado.

O sociólogo polonês Zygmunt Bauman afirmava que os desempregados eram considerados como o exército de reserva da mão-de-obra. Quando se encontravam temporariamente sem emprego por motivo de saúde, enfermidade ou dificuldades econômicas correntes, deviam ser preparados para reassumir o emprego, quando aptos. Prepará-los era, geralmente, a tarefa reconhecida e a incumbência explícita ou tácita dos poderes públicos. Mas, concluía, lamentando, que isso "já não acontece assim. Exceto nos nostálgicos e cada vez mais demagógicos textos de propaganda eleitoral, os sem emprego deixaram de ser um exército de reserva da mão-de-obra"14.

O que acaba por ocorrer com essa parcela da população? Diante disso, os trabalhadores que apenas possuem em si sua força de trabalho para vender assistem atônitos às sucessivas reestruturações produtivas que, a pretexto de sanearem a crise econômica, agravam as crises sociais, desagregam os vínculos sociais e adoecem os trabalhadores. A precarização da legislação trabalhista é uma boa prova disso, o Código de Processo Civil, que normalmente viabiliza o direito das grandes corporações, foi discutido por três anos e meio, ao tempo que as alterações no Direito do Trabalho foram impostas em seis meses e sem o pertinente e necessário debate.

A respeito dos pontos mais conectados ao trabalho escravo, serão analisadas a seguir as alterações da Lei n 6.019/74, na qual se incluiu a terceirização, e a Lei $n^{\circ}$ 13.467/17, intitulada de "Reforma Trabalhista".

13 BAUMAN, Zygmunt; BORDONI, Carlo. Estado de Crise. Tradução Renato Aguiar. Rio de Janeiro: Jorge Zahar, 2016. p. 21.

14 BAUMAN, Zygmunt. Mal-Estar na Pós-modernidade. São Paulo: Jorge Zahar, 1998. p. 50. 


\section{RETROCESSOS EXPLÍCITOS: A REGULAMENTAÇÃO DA TERCEIRIZAÇÃO E A REFORMA TRABALHISTA}

Conforme já afirmado, os centros de produção se deslocaram ao longo do século XX, com o fenômeno da reestruturação produtiva - e assim continuam, se movimentando em busca da mão de obra mais barata e acessível. O Brasil possuía, até o ano de 2017, mecanismos que bloqueavam a ação ampla de práticas diretamente relacionadas à exploração do trabalho, que, em sua faceta mais precarizante, abrange o trabalho escravo contemporâneo. No entanto, com a aprovação das leis $n^{\circ}$ 13.429/2017 e 13.467/2017, o capital mostra novamente sua cara, comprovando sua crise cíclica, que deve ser sanada com níveis de exploração ainda maiores. Níveis estes travestidos de salvaguardas econômicas, mas que indicam modalidades que incontestavelmente operam retrocessos sociais. Cada uma dessas normativas merece, portanto, um breve - mas iniciático - exame.

A terceirização atual, como fenômeno do mundo globalizado, pode ser definida como a intermediação de mão de obra por meio da produção em rede ou da contratação por empresa interposta, substituindo os empregados da tomadora pelos da prestadora de serviços. É, dessa forma, um processo de esfacelamento. Na conjuntura do trabalho escravo, proporciona maior facilidade de precarização e dificulta a responsabilidade empresarial. A fragmentação da empresa retira do primeiro plano os capitalistas centrais, que de fato receberão a maior parte do lucro com a atividade que venha a ser desenvolvida pelos trabalhadores, colocando em seus lugares, como responsáveis diretos, os intermediários. Perceba-se, porém, que a situação atual ainda faz com que esses intermediários adotem o mesmo procedimento, colocando em seus próprios lugares outros terceiros, que também repetem o ato, formando quarteirizações, quinteirizações e assim por diante. A função dos últimos da cadeia se resume, então, a cumprir partes do processo produtivo, que caberia ao tomador de serviços executar. Havia entendimento sedimentado na doutrina, nesse sentido, de duas maneiras de se transferir a responsabilidade sobre os trabalhadores, conforme explicou Márcio Túlio Viana, que denomina tais formas de terceirização como interna e externa:

Foi o que ensaiamos há já bastante tempo, num primeiro esforço de classificação, chamando uma de "interna" e a outra de "externa". Na primeira, a empresa traz trabalhadores alheios para dentro de si. Na segunda, joga para fora de si não só trabalhadores seus, como etapas de seu ciclo produtivo.

Uma e outra podem ser vistas como faces de um mesmo fenômeno. Ainda assim, têm componentes diferentes, geram efeitos nem sempre iguais e podem ser combatidas por meios também distintos. [...]

\section{$[\ldots]$}

A terceirização externa lembra o trabalho por conta própria. Uma empresa contrata a outra, mas o que lhe interessa é o produto final. Por isso, só ao término da produção passa a ter propriedade sobre ele. Já a terceirização 


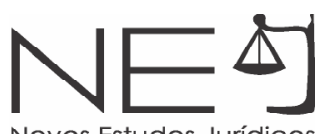

interna se articula com o trabalho por conta alheia. A empresa tomadora vai se apropriando do trabalho dos terceirizados na medida em que eles o executam. ${ }^{15}$

Embora diferentes em alguns sentidos, tanto na terceirização externa - quando todo o ciclo produtivo incumbe a outras empresas - quanto na interna - na qual a tomadora ainda tem certo controle direto sobre os trabalhadores durante o processo de produção -, existem conexões diante da transferência de responsabilidade. Um desses elos é, exatamente, a maior incidência de casos de trabalho escravo contemporâneo. Especificamente nesse sentido, a diferenciação proposta durante muitos anos, em especial a de proibição da terceirização de atividade fim e liberação de atividade meio, vem se tornando menos relevante do ponto de vista prático, em especial frente às quarteirizações e quinteirizações.

A terceirização, no Brasil, vinha sendo controlada - de certa forma - pela utilizaçãojurisprudencial da Súmula 331, que determinava, em especial: (i) a ilegalidade da contratação interposta, salvo no caso de trabalho temporário; (ii) a ausência de vínculo empregatício nos serviços de vigilância, conservação e limpeza, além dos serviços ligados à atividade-meio, inexistentes a pessoalidade e a subordinação direta; (iii) a responsabilidade subsidiária do tomador, tendo participado da relação processual; (iv) a responsabilidade subsidiária da Administração Pública, em conduta culposa, mesmo não gerando vínculo de emprego; e (v) a abrangência de todas as verbas decorrentes da condenação na responsabilidade subsidiária. Inexistente a lei, o direcionamento jurisprudencial acima referido era aplicado aos casos submetidos à apreciação judicial, o que realizava em parte a justiça.

E as autoras afirmam ser apenas uma parte, por entenderem que a permissão de terceirização de atividades-meio, vigilância, trabalho temporário, conservação e limpeza e outras questões como a necessidade de constar do título executivo judicial - não eram efetivas contra a prática. A terceirização funciona em uma lógica óbvia do capitalismo: vence o mais barato. Não há motivo para terceirizar se o resultado final não for mais lucrativo que o original.

E, no caso do trabalho escravo, a lucratividade é ainda maior, pois as cadeias de produção que se formam, ao mesmo tempo em que levam a produção a pontas mais extremas, diminuem de forma proporcional os ganhos salariais e as condições de trabalho, aumentando as jornadas e piorando o meio ambiente do trabalho. Se a situação não era, de fato, a mais benéfica possível, foi necessário reformular o entendimento e, a pretexto de regulamentar para salvar a economia, a Lei $n^{\circ}$ 6.019/74 sofreu alterações em março de 2017.

Conforme a Lei no 13.429/17, a Lei do Trabalho Temporário passou a reger também as relações de trabalho na empresa de prestação e nas respectivas tomadoras e contratantes $\left(\operatorname{art} .1^{\circ}\right)$. A primeira inserção já foi suficientemente clara:

15 VIANA, Márcio Túlio. O que é a terceirização? In: Blog da Boitempo, $1^{\circ}$ abr. 2015. Disponível em: <http:// blogdaboitempo.com.br/2015/04/01/o-que-e-a-terceirizacao/>. Acesso em: 12 jun. 2019. 
Art. $4^{\circ}-\mathrm{A}$. Empresa prestadora de serviços a terceiros é a pessoa jurídica de direito privado destinada a prestar à contratante serviços determinados e específicos.

§ 1ㅇ A empresa prestadora de serviços contrata, remunera e dirige o trabalho realizado por seus trabalhadores, ou subcontrata outras empresas para realização desses serviços.

\section{§ 2ำ Não se configura vínculo empregatício entre os trabalhadores, ou sócios das empresas prestadoras de serviços, qualquer que seja o seu ramo, e a empresa contratante. ${ }^{16}$}

A responsabilidade, que, antes, no conceito de terceirização ilícita, era solidária, passou a ser subsidiária e apenas no tocante ao período de prestação ("a empresa contratante é subsidiariamente responsável pelas obrigações trabalhistas referentes ao período em que ocorrer a prestação de serviços [...]" - art. 5०-A, $5^{\circ}$ ). Para a paziguar os ânimos, foi inserida uma multa (art. 19-A) aos descumpridores, referenciando-se o Título VII da CLT para sua fiscalização. No entanto, para completar a liberalidade, os "contratos em vigência, se as partes assim acordarem, poderão ser adequados aos termos desta lei" (art. 19-C).

Se, aos olhos leigos, a lei parece benéfica, regulamentando algo que ainda não dispunha de legislação específica, o estudo histórico demonstra o retrocesso social. Declínio que foi aumentado com a edição da Lei n 13.467/17 - Reforma Trabalhista -, que, em seus últimos dispositivos, alterou novamente a Lei $n^{\circ} 6.019 / 74$.

O conceito de terceirização conseguiu a façanha de ficar ainda mais amplo:

Art. $4^{\circ}$-A. Considera-se prestação de serviços a terceiros a transferência feita pela contratante da execução de quaisquer de suas atividades, inclusive sua atividade principal, à pessoa jurídica de direito privado prestadora de serviços que possua capacidade econômica compatível com a sua execução. ${ }^{17}$

Se, na inserção de março, a contratante era a pessoa física ou jurídica que celebrava contrato com empresa de prestação de serviços determinados e específicos, na lei de julho, essa última empresa pode prestar qualquer serviço, relacionado "a quaisquer de suas atividades, inclusive sua atividade principal" (art. 5-A). De forma cristalina, a adição reforça o fim da garantia estabelecida no item III da Súmula 331.

16 BRASIL. Lei no 13.429, de 31 de março de 2017. Altera dispositivos da Lei no 6.019, de 3 de janeiro de 1974, que dispõe sobre o trabalho temporário nas empresas urbanas e dá outras providências; e dispõe sobre as relações de trabalho na empresa de prestação de serviços a terceiros. Diário Oficial da União, 31 mar. 2017. Disponível em: <http://www.planalto.gov.br/ccivil_03/_Ato2015-2018/2017/Lei/L13429.htm>. Acesso em: 12 jun. 2019. (sem grifos no original).

17 BRASIL. Lei $n^{\circ}$ 13.467, de 13 de julho de 2017. Altera a Consolidação das Leis do Trabalho (CLT), aprovada pelo Decreto-Lei no 5.452, de 10 de maio de 1943, e as Leis nos 6.019, de 3 de janeiro de 1974, 8.036, de 11 de maio de 1990, e 8.212, de 24 de julho de 1991, a fim de adequar a legislação às novas relações de trabalho. Diário Oficial da União, 14 jul. 2017. Disponível em: <http://www.planalto.gov.br/ccivil_03/_ato2015-2018/2017/ lei/L13467.htm>. Acesso em: 12 jun. 2019. (sem grifos no original). 
Essa alteração dupla (pela Lei no 13.429/17 e pela Lei $n^{\circ} 13.467 / 17$ ) nem sequer foi debatida, ocasionando verdadeira construção legislativa em descompasso com os mandamentos da Legística, que torna quase incompreensível a Lei do Trabalho Temporário, com junção de pedaços de artigos revogados e inseridos. Tudo isso sob a justificativa "anti-crise".

A existência de milhões de trabalhadores terceirizados, percebendo menores salários, com rotatividade dobrada, jornada superior aos não terceirizados e maior ocorrência de acidentes e mortes decorrentes do trabalho, são apenas alguns dos problemas a serem enfrentados, vez que também coube a esses trabalhadores suportarem outro ônus da precariedade: as hipóteses de trabalho escravo. Além de desembocar em consequências individuais, visto que tal parcela de obreiros se sujeita ao maior índice acidentário, a prática da terceirização leva ainda a consequências coletivas e sociais, ao eximirem as empresas da eliminação de riscos à saúde, à segurança e à própria vida e dignidade, optando por uma sub-neutralização do perigo, que muitas vezes nem sequer é alcançada. E essa isenção da eliminação dos riscos ficou clara na inserção do inciso II, do art. $4^{\circ}-C_{\text {, }}$ que diz ser dever da tomadora assegurar as mesmas condições de proteção à saúde, segurança no trabalho e instalações adequadas apenas quando os terceirizados trabalharem em suas dependências.

Conquanto seja norma de ordem pública, a supressão dos riscos do trabalho tem sua eficácia mitigada em face dos interesses de mercado, que por diversas razões colocam a terceirização como solução de problemas econômicos, quando em realidade é ela a potencial causadora desses, vez que impacta diretamente no erário público, com o aumento de custeio de verbas de seguridade social, diminuição salarial, além de refletir nas verbas do Fundo de Amparo ao Trabalhador (FAT). Fundo este que depois recebe receitas de condenações por trabalho escravo, ironicamente. Ao lado dos comprometimentos do próprio Estado com os gastos advindos dos acidentes e mortes no trabalho, há o lado individual que atinge os direitos fundamentais dos trabalhadores. Assim, a terceirização também fere o direito à vida e ao trabalho digno, como informam Márcio Túlio Viana, Gabriela Neves Delgado e Helder Santos Amorim:

Em termos objetivos, a terceirização afeta os terceirizados, que em geral trabalham em condições mais precárias; os permanentes, cujos salários, por isso mesmo, tendem a se aviltar; e às vezes a própria empresa tomadora, que além de lidar com o embate histórico entre capital e trabalho, vê-se a braços com um conflito inédito entre trabalho e trabalho.

Já em termos subjetivos, a terceirização atravessa as paredes do Parlamento para invadir corações e mentes, dificultando não só a luta para se pôr o direito, mas a luta pelo direito posto. E isso vale tanto para o terceirizado como para o efetivo, pois o que o primeiro transmite ao segundo não é apenas a degradação do salário ou do trabalho, mas o individualismo, a concorrência, a corrosão do caráter. ${ }^{18}$

18 VIANA, Márcio Túlio; DELGADO, Gabriela Neves; AMORIM, Helder Santos. Terceirização - aspectos gerais. A última decisão do STF e a Súmula 331 do TST. Novos enfoques. Rev. TST, Brasília, v. 77, n. 1, p. 54-84, jan./mar. 2011. Disponível em: <http://siabi.trt4.jus.br/biblioteca/acervo/Doutrina/artigos/Revista\%20do\%20Tribunal\%20 Superior\%20do\%20Trabalho/2011/n\%201/Terceiriza\%C3\%A7\%C3\%A3o\%20-\%20aspectos\%20gerais\%20A\%20 \%C3\%BAltima\%20decis\%C3\%A3o\%20do\%20STF\%20e\%20a\%20S\%C3\%BAmula\%20n\%20331\%20do\%20 TST\%20Novos\%20enfoques.pdf>. Acesso em: 12 jun. 2019. p. 59. 
A exclusão é, portanto, mais um dos efeitos do fenômeno terceirizante, levando à fragmentação de sindicatos, à degradação das condições sociais, à incapacidade para o trabalho e até à morte. Não à toa, Grijalbo Fernandes Coutinho a denomina "máquina de moer gente trabalhadora", por ser "verdadeira miséria social imposta pelo modelo econômico em vigor"19. Por isso:

Princípios constitucionais inerentes à vida digna, normas constitucionais asseguradoras de um ambiente saudável de trabalho, princípios orientadores do Direito do Trabalho, pactos e normas internacionais cuidando da garantia do exercício dos Direitos Humanos pelos trabalhadores, sem nenhuma hesitação, são reiteradamente solapados pelas relações de trabalho terceirizadas no Brasil.

Tanto é assim que os números apresentados revelam a tragédia social decorrente da terceirização, com elevados índices de trabalho escravo contemporâneo, ofensa aos direitos imateriais dos trabalhadores, fragmentação sindical, invisibilidade social, mortes e mutilações relacionados ao trabalho terceirizado. ${ }^{20}$

A terceirização, quando observada pela ótica da precarização, mostra sua verdadeira face. A imensa cadeia que vai se formando com a intermediação de mão-de-obra torna quase impossível estabelecer a responsabilização do capital pelos danos que causa em busca de lucro. Assim, possibilita um aumento cada vez maior de acidentes, doenças e mortes, criando um ciclo vicioso de precarização. E esse ciclo tem como uma de suas bases a utilização da melhor forma de lucro hoje conhecida: o trabalho escravo, no qual o obreiro vale tão pouco que pode ser descartado a qualquer tempo e substituído por outro que, em meio à "crise", "necessitará" dessa sujeição.

Porém, não é apenas no trabalho terceirizado que os problemas têm a perspectiva de incremento. Embora a Lei n 13.467/17 também tenha alterado os dispositivos apontados relacionados à terceirização, suas modificações atingem um número ainda maior de trabalhadores e - pior impedem a efetividade do combate judicial ao trabalho escravo, como será demonstrado a seguir.

\section{LEI No 13.467/17: REFORMA TRABALHISTA E SUAS MODIFICAÇÕES NOS DISPOSITIVOS CELETISTAS}

A Reforma Trabalhista modificou tanto a essência do Direito do Trabalho que torna difícil o exame de quais dispositivos têm mais repercussões no combate ao trabalho escravo.

Alterou, dessa forma, o poder do juiz de analisar o mérito das negociações coletivas (art. 80, $\S 3^{\circ}$ ), a responsabilidade do sócio retirante e da sucessão empresarial (arts. 10-A e 448-A), introduziu a prescrição intercorrente e alterou o prazo das prestações sucessivas, que agora estão sujeitas à

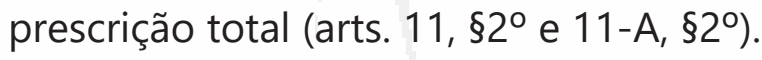

19 COUTINHO, Grijalbo Fernandes. Terceirização: máquina de moer gente trabalhadora. A inexorável relação entre a nova merchandage e a degradação laboral, as mortes e mutilações no trabalho. São Paulo: LTR, 2015. p. 256.

20 COUTINHO, Grijalbo Fernandes. Terceirização: máquina de moer gente trabalhadora. A inexorável relação entre a nova merchandage e a degradação laboral, as mortes e mutilações no trabalho. São Paulo: LTR, 2015. p. 257. 
Optou pela prevalência do negociado sobre o legislado (art. 611-A) em matéria de jornada, intervalo, remuneração por produtividade e desempenho, permitindo negociar até o grau de insalubridade e, ainda, dar termo de quitação anual pelas verbas integrais do contrato (art. 507-B). Excluiu a necessidade de acompanhamento sindical (art. 477-A) e possibilitou acordos para a extinção do contrato de trabalho (art. 484-A). Desconstruiu a Súmula 437 do TST (art. 71, §4) e permitiu a pactuação por acordo individual da jornada 12 × 36 a qualquer tipo de trabalho (art. 59-A), vedando o pagamento de horas in itinere (art. $58, \S 2^{\circ}$ ).

Para este artigo, no entanto, foram escolhidos temas da maior importância para a temática analisada, referentes à descaracterização do grupo econômico, às fontes e princípios do Direito do Trabalho e ao tabelamento dos danos extrapatrimoniais.

\subsection{A DESCARACTERIZAÇÃO DE GRUPO ECONÔMICO DO ART. $2^{\circ}$}

Ao abordar a problemática da terceirização, era praxe verificar que, na verdade, a subcontratação de mão de obra operava apenas dentro de um círculo empresarial, o qual, pela disposição anterior da CLT, se configurava quase sempre como grupo de empregadores. A previsão era ampla:

Art. $2^{\circ} .[\ldots]$

$\S 2^{\circ}$ - Sempre que uma ou mais empresas, tendo, embora, cada uma delas, personalidadejurídica própria, estiverem sob a direção, controle ou administração de outra, constituindo grupo industrial, comercial ou de qualquer outra atividade econômica, serão, para os efeitos da relação de emprego, solidariamente responsáveis a empresa principal e cada uma das subordinadas. ${ }^{21}$

O grupo de empregadores sempre foi a saída mais fácil e completa na responsabilização do trabalho escravo, por sua natureza totalmente diferenciada. Inclusive, Margarida Barreto de Almeida indicou em sua tese de doutorado outra possibilidade interpretativa, afirmando que:

Em relação ao agrupamento de empresas, a tese opta por tratá-lo como gênero do qual se destacam duas espécies: a empresa de grupo (concepção estrutural) e o grupo de empresas (concepção orgânica). A primeira se apresenta de forma multissocietária, embora não deixe de ser unidade produtiva de bens e serviços; suas células produtivas se vinculam ao mesmo centro de convergência, por meio do controle feito pela sociedade-mãe. O grupo de empresas, por sua vez, seria aquele formado por todas as demais interligações de empresas, em contexto de coordenação ou de subordinação à sociedade controladora. ${ }^{22}$

21 BRASIL. Decreto-lei n ${ }^{\circ} 5.452$, de $1^{\circ}$ de maio de 1943. Aprova a Consolidação das Leis do Trabalho. Diário Oficial da União, 9 ago. 1943. Disponível em: <http://www.planalto.gov.br/ccivil_03/decreto-lei/Del5452.htm>. Acesso em: 12 jun. 2019.

22 ALMEIDA, Margarida Barreto de. Empresa de grupo e grupo de empresa: desvendando a complexidade subjetiva do empregador. $199 \mathrm{f}$. Tese (Doutorado em Direito). Faculdade de Direito da UFMG e Università deli Studi di Roma - Tor Vergata, 2017. pré-textual. 
Por óbvio, esta foi a primeira alteração da Reforma Trabalhista, que indicou como grupo empresarial apenas o grupo econômico, que não se configura com a mera identidade de sócios:

§ 2o Sempre que uma ou mais empresas, tendo, embora, cada uma delas, personalidade jurídica própria, estiverem sob a direção, controle ou administração de outra, ou ainda quando, mesmo guardando cada uma sua autonomia, integrem grupo econômico, serão responsáveis solidariamente pelas obrigações decorrentes da relação de emprego.

§ 3 Não caracteriza grupo econômico a mera identidade de sócios, sendo necessárias, para a configuração do grupo, a demonstração do interesse integrado, a efetiva comunhão de interesses e a atuação conjunta das empresas dele integrantes. ${ }^{23}$

A repercussão envolve diretamente os terceirizados, que caem nas armadilhas do trabalho escravo: se não é possível vinculá-los a uma estrutura maior (grupo de empresas ou empresa de grupo), a indenização jamais chegará, pois é sabido que, quanto mais se terceiriza, se subdivide a empresa, menor é seu potencial pagador. Além disso, a sanção moral ao topo da cadeia também se tornará cada vez mais difícil.

\section{$2.2 \mathrm{O} \S 1^{\circ}$ DO ART. $8^{\circ}$ E A DESNECESSIDADE DE RESPEITO AOS PRINCÍPIOS DO DIREITO DO TRABALHO}

Ao tratar da aplicação do Direito do Trabalho, seus princípios e fontes sempre foram muito claros e, na integração com outros ramos, deviam ser respeitados. Pelo menos, era o que indicava o art. $8^{\circ}$ da CLT, que agora possui outra redação.

A regra sempre foi das mais repetidas: é possível aplicar outros conceitos e utilizar o direito comum como fonte subsidiária, observada a compatibilidade com os princípios trabalhistas (parágrafo único do art. $8^{\circ}$ ). Em um jogo de exclusão de palavras, o dispositivo se transformou em $\S 1^{\circ}$, para constar apenas que "o direito comum será fonte subsidiária do direito do trabalho"24.

O que aparenta não ser excessivamente danoso, em verdade, ao se conectar com os elementos que o combate ao trabalho escravo utiliza, determina a subutilização do princípio da proteção e do próprio princípio da dignidade. Ao julgar um caso indenizatório relativo a jornadas exaustivas e

23 BRASIL. Lei $n^{\circ}$ 13.467, de 13 de julho de 2017. Altera a Consolidação das Leis do Trabalho (CLT), aprovada pelo Decreto-Lei no 5.452, de 10 de maio de 1943, e as Leis nos 6.019, de 3 de janeiro de 1974, 8.036, de 11 de maio de 1990, e 8.212, de 24 de julho de 1991, a fim de adequar a legislação às novas relações de trabalho. Diário Oficial da União, 14 jul. 2017. Disponível em: <http://www.planalto.gov.br/ccivil_03/_ato2015-2018/2017/ lei/L13467.htm>. Acesso em: 12 jun. 2019.

24 BRASIL. Lei $n^{\circ}$ 13.467, de 13 de julho de 2017. Altera a Consolidação das Leis do Trabalho (CLT), aprovada pelo Decreto-Lei no 5.452, de 10 de maio de 1943, e as Leis nos 6.019, de 3 de janeiro de 1974, 8.036, de 11 de maio de 1990, e 8.212, de 24 de julho de 1991, a fim de adequar a legislação às novas relações de trabalho. Diário Oficial da União, 14 jul. 2017. Disponível em: <http://www.planalto.gov.br/ccivil_03/_ato2015-2018/2017/ lei/L13467.htm>. Acesso em: 12 jun. 2019. 
condições degradantes, por exemplo, são esses os princípios informadores, independentemente, por outro lado, daqueles afetos ao Direito Penal, ramo no qual o conceito se localiza.

Possibilitar a aplicação de fontes de outros ramos sem o devido respeito e observância ao que rege o Direito do Trabalho em sua essência causará confusão na utilização dos conceitos, em especial porque este ramo cumpre algo que aos demais não cabe: o objetivo de justiça social.

O trabalho escravo, nesse sentido, pode ser combatido não apenas com a sanção criminal, mas também pelo fortalecimento do próprio Direito do Trabalho, que protege o que aquele fere: o trabalho digno. Ao tratar das condições a que os trabalhadores são submetidos, não se pode olvidar, da mesma forma, a imprescindibilidade do cumprimento da justiça social como princípio basilar. É esse princípio que, como faceta da dignidade humana, promove o homem a centro convergente de direitos humanos, afirmando José Joaquim Gomes Canotilho que:

[...] os direitos sociais e econômicos (ex.: direito dos trabalhadores, direito à assistência, direito à educação), uma vez alcançados e conquistados, passam a constituir, simultaneamente, uma garantia institucional e um direito subjectivo. Desta forma, [...] o princípio em análise justifica, pelo menos, a subtracção à livre e oportunística disposição do legislador, da diminuição de direitos adquiridos, em clara violação do princípio da proteção da confiança e da segurança dos cidadãos no âmbito econômico, social e cultural. [...] constitui um limite jurídico do legislador e, ao mesmo, uma obrigação de prossecução de uma política congruente com os direitos concretos e expectativas subjectivamente alicerçadas. Esta proibição justificará sanção de inconstitucionalidade relativamente a normas manifestamente aniquiladoras da chamada "justiça social". 25

De acordo com José Afonso da Silva ${ }^{26}$, a empresa, como propriedade, deve também cumprir sua função social, estando vinculada ao princípio da justiça social. É exatamente em decorrência deste princípio que se optou por inserir no art. 243 da Constituição de 1988 a previsão para a expropriação de terras em que for encontrado trabalho escravo. Dela também se depreende a defesa do meioambiente, gênero do qual se desdobra o meio ambiente do trabalho, também tutelado pela proteção dos direitos sociais. Além do art. art. 170, o princípio também teria como fundamento os arts. $1^{\circ}, \mathrm{IV}$, $3^{\circ}$, I e III, e $5^{\circ}$, XXIII, da Constituição de 1988. ${ }^{27}$ A distinção entre o Direito do Trabalho e os demais ramos é indicativo suficiente a demonstrar que a previsão alterada do art. $8^{\circ}$ poderá trazer a essa seara entendimentos que descumprem seus objetivos, sob a justificativa não só de "crise econômica", como também da possibilidade de usar outros princípios. Exemplo claro de entendimento político da inserção de espécies relativas a outros ramos e que se baseiam em outros pontos de toque é o tabelamento do dano extrapatrimonial.

25 CANOTILHO, José Joaquim Gomes. Direito Constitucional. 6. ed. Coimbra: Almedina, 1993. p. $468-469$.

26 SILVA, José Afonso da. Curso de direito constitucional positivo. 23. ed. São Paulo: Malheiros, 2004.

27 DELGADO, Maurício Godinho. Direitos fundamentais na relação de Trabalho. In: SILVA, Alessandro da; SOUTO MAIOR, Jorge Luiz; FELIPPE, Kenarik Boujikian; SEMER, Marcelo (Coord.). Direitos Humanos: essência do Direito do Trabalho. São Paulo: LTr, 2007. p. 73. 


\subsection{O TABELAMENTO DO DANO EXTRAPATRIMONIAL DE ACORDO COM O SALÁRIO CONTRATUAL DO EMPREGADO (ARTS. 223-A A 223-G)}

Como lei infraconstitucional, a previsão do art. 149 do CP/40 desafia a aplicação principiológica, unindo ainda não apenas uma seara, mas duas: a trabalhista e a penal. Tal junção traz implicações juslaborais, em especial para a aplicação do dano moral individual, das obrigações de ações civis públicas do Ministério Público do Trabalho e das multas dos autos de infração exarados pelo Ministério do Trabalho. A Justiça do Trabalho, muitas vezes, reduz sua função repressiva no oferecimento de dano moral ao trabalhador submetido a essas condições. Seja em sua face individual (em reclamatória individual) ou coletiva (via Ação Civil Pública), os danos sempre obtiveram valor elevado, diante da total perda da dignidade obreira. Isso dificilmente acontecerá a partir de agora, com o tabelamento do dano extrapatrimonial, que abrange qualquer ofensa à esfera moral ou existencial da pessoa física ou jurídica, que passa a ser a única titular do direito à reparação (art. 223-B). Os bens tutelados seriam a honra, a imagem, a intimidade, a liberdade de ação, a autoestima, a sexualidade, a saúde, o lazer e a integridade física (art. 223-C).

Para sua concessão, caberá ao juiz analisar nada menos que doze quesitos, como intensidade do sofrimento, possibilidade de superação, condições em que ocorreu a ofensa, grau de dolo ou culpa, situação social e econômica, entre muitos outros (art. 223-G), fixando a indenização da seguinte:

§ 1 Se julgar procedente o pedido, o juízo fixará a indenização a ser paga, a cada um dos ofendidos, em um dos seguintes parâmetros, vedada a acumulação:

I - ofensa de natureza leve, até três vezes o último salário contratual do ofendido;

II - ofensa de natureza média, até cinco vezes o último salário contratual do ofendido;

III - ofensa de natureza grave, até vinte vezes o último salário contratual do ofendido;

IV - ofensa de natureza gravíssima, até cinquenta vezes o último salário contratual do ofendido.

§ 2 Se o ofendido for pessoa jurídica, a indenização será fixada com observância dos mesmos parâmetros estabelecidos no § 1ㅇdeste artigo, mas em relação ao salário contratual do ofensor.

§ 3N Na reincidência entre partes idênticas, o juízo poderá elevar ao dobro o valor da indenização. ${ }^{28}$

28 BRASIL. Lei no 13.429, de 31 de março de 2017. Altera dispositivos da Lei no 6.019, de 3 de janeiro de 1974, que dispõe sobre o trabalho temporário nas empresas urbanas e dá outras providências; e dispõe sobre as relações de trabalho na empresa de prestação de serviços a terceiros. Diário Oficial da União, 31 mar. 2017. Disponível em: <http://www.planalto.gov.br/ccivil_03/_Ato2015-2018/2017/Lei/L13429.htm>. Acesso em: 12 jun. 2019. 
Obviamente, o trabalhador escravizado não possui salário contratual, sendo-lhe fixado o salário mínimo que, mesmo diante de ofensa gravíssima (o que a jurisprudência parece indicar não o ser), implicaria o recebimento máximo de $\mathrm{R} \$ 46.850,00$ de acordo com o salário mínimo de 2017. Mesmo em seu teto, o valor é menor do que as condenações tradicionais, forçando um duro golpe à sanção.

As três inserções aqui escolhidas conseguem determinar quase o fim do combate ao trabalho escravo: enquanto a primeira - grupo econômico - impede sua própria configuração dentro da cadeia empresarial, a utilização de princípios alheios ao Direito do Trabalho, sem respeitar sua função reitora, prejudica a compreensão do fenômeno, que, ao final, receberá sanção muito aquém ao esperado.

Não bastasse a situação brasileira de alterações legislativas, que foram demonstradas de forma breve, o aumento da escravidão contemporânea, quando analisado sob a ótica da utilização da "crise econômica" como pretexto para retrocessos sociais, também se relaciona a um fenômeno internacional, que convém denominar como "Dumping Social".

\section{A CONSEQUÊNCIA DA TERCEIRIZAÇÃO, DA DESCARACTERIZAÇÃO DO GRUPO ECONÔMICO, DA DESNECESSIDADE DE RESPEITO A PRINCÍPIOS E DO TABELAMENTO DE DANOS: O DUMPING SOCIAL}

Conforme já foi dito acima, o fenômeno do "Dumping social" constitui "estratégia" para sanear a crise. Essa nova divisão internacional do trabalho, impulsionada pelo desenvolvimento científico e tecnológico, fez ruir as barreiras existentes no mundo.

Todas essas interações tecnológicas promoveram o encurtamento das distâncias entre os povos e, sobretudo, entre os mercados. O irônico é que o que deveria ser um ingrediente para promover o desenvolvimento social passa a ser o motivo do caos social global. Segundo Lojkine, a divisão internacional do trabalho seria sempre dominada pela oposição entre o salariado dos países "ricos" e o dos países "pobres": os primeiros concentrariam altos salários e altas qualificações, os centros de decisão e os grandes polos de inovação técnico-científica; os segundos não teriam mais que baixos salários e baixas qualificações. ${ }^{29}$

Tal ideia toca diretamente nesse novo conceito de capitalismo informacional/trabalho imaterial, que traz consequências atuais para o Brasil nos aspectos analisados nas leis n 13.429 e 13.467/17. O estudo de Carlo Benito Cosentino acerca do assunto revela informações preciosas acerca da questão: ${ }^{30}$

As grandes indústrias mantêm as suas matrizes, suas sedes, nos grandes centros urbanos dos países desenvolvidos. Nesses locais, são preservados, apenas, os postos de trabalho inteligentes, aqueles que pensam a corporação, dirigindo-a, projetando-a, desenvolvendo-a, programando-a.

29 LOJKINE, Jean. A revolução Informacional. 3. ed. São Paulo: Cortez, 2002. p. 232.

30 O programa de pós-graduação da Universidade Federal de Pernambuco, liderado pelo prof. Dr. Everaldo Lopes de Andrade é referência nacional nos estudos do Direito do Trabalho associado à teoria crítica. 
Enquanto isso, o operacional é todo implantado nos países em desenvolvimento, especialmente, na Ásia e na América do Sul. É que, nessas áreas, especialmente no oriente, o Direito do Trabalho não teve chance de se desenvolver adequadamente. E por esta razão, a sociedade do trabalho, tal como a da Europa Ocidental no início da revolução industrial, deixa-se explorar. ${ }^{31}$

Quanto menos leis trabalhistas expressivas e justiça do trabalho atuante, menos gastos com recursos humanos e, dessa forma, por sobre suor e sangue da classe trabalhadora dos países em desenvolvimento, o ultraliberalismo global, a partir de suas indústrias, fabrica seus produtos a custos baixíssimos para, na sequência, distribuí-los por todo o globo.

A "teoria do dumping social", originou-se a partir do contexto de globalização da economia, com o consequente desmembramento das plantas industriais, a exemplo da produção de tênis e de bolas esportivas. Nesses exemplos, constatou-se nas grandes indústrias o movimento de transferir parte da sua produção para países asiáticos, nos quais a mão-de-obra era sabidamente barata e carente regulamentação laboral. Tal forma de exploração viabiliza em muitos casos a exploração do trabalho infantil e em condições análogas às de escravo.

A expressão dumping provém do verbo inglês dump, significando desfazer-se de algo e depositá-lo em determinado local, como se fosse lixo. No mercado internacional uma empresa executa dumping quando: (a) detém certo poder de estipular preço de seu produto no mercado local (empresa em concorrência imperfeita); e (b) perspectiva de aumentar o lucro por meio de venda no mercado internacional. Essa empresa, então, vende no mercado externo seu produto a preço inferior ao vendido no mercado local, provocando elevada perda de bem-estar ao consumidor nacional, porque os residentes locais não conseguem comprar o produto a ser vendido no estrangeiro. ${ }^{32}$

Assim, consideram-se "Dumping Social" as agressões reincidentes e inescusáveis aos direitos trabalhistas que geram danos à sociedade, com o objetivo de obter vantagem indevida perante a concorrência. Tais condutas acabam estimulando o descumprimento das normas trabalhistas, gerando um ciclo vicioso de desrespeito aos direitos sociais constitucionalmente garantidos.

Uma análise do cenário brasileiro revela de forma assombrosa a realidade do que aqui se discute. Bastante pertinente a ponderação de Lojkine:

Uma recente pesquisa sobre o impacto da microeletrônica sobre a organização do trabalho demonstra claramente as transformações operadas, no Brasil,

31 COSENTINO, Carlo Benito. Os trabalhadores do conhecimento e o trabalho imaterial: As novas possibilidades de reinvenção das lutas coletivas. 156 f. Dissertação (Mestrado em Direito). Recife, Programa de Pós-Graduação em Direito da UFPE, 2016. Disponível em: <http://repositorio.ufpe.br/bitstream/handle/123456789/18539/ CARLO\%20BENITO\%20Disserta\%C3\%A7\%C3\%A3o.pdf?sequence=1\&isAllowed=y>. Acesso em: 12 jun. 2019. p. 38.

32 FRAHM, Catarina; VILLATORE, Marco Antônio César. Dumping Social e o Direito do Trabalho. s/d. Disponível em: <www.scribd.com.br>. Acesso em: 12 jun. 2019. p. 27. 
na composição da mão-de-obra da indústria automobilística e da máquinaferramenta: a parte da mão-de-obra indireta e do trabalho intelectual aumenta em relação à da mão-de-obra direta - o que confirma plenamente as tendências que pudemos observar na indústria automobilística francesa e no conjunto de atividades automatizadas. ${ }^{33}$

Aparentemente se pode pensar que não há relação entre o "Dumping Social" e o aumento da escravidão contemporânea, contudo, como foi abordado em relação à terceirização e às novas formas de retirar direitos trabalhistas, a precarização resultante da busca por baratear os custos da produção revela a sua pior face.

De acordo com o relatório da ONG Walk Free, publicado em maio de 2016, ao menos 45,8 milhões de pessoas no mundo vivem hoje uma situação de escravidão contemporânea, e o Índice Global da Escravidão estima que o Brasil tenha 161 mil pessoas em condições análogas às de escravos.

Ainda segundo a pesquisa, cinco países do mundo (Índia, China, Paquistão, Bangladesh e Uzbequistão) comportam 58\% do total de "escravizados". A Índia possui, sozinha 18,4 milhões de pessoas nesta situação. Na Coreia do Norte a proporção é de 1 para cada 20 pessoas, aproximadamente, esteja nessa situação (1,1 milhão no total). ${ }^{34}$

O estudo aponta ainda que a pobreza e a falta de oportunidade desempenham um papel importante no aumento da vulnerabilidade à escravidão moderna. O que em verdade está sendo criado no cenário brasileiro com as alterações da Reforma Trabalhista e da regulamentação da terceirização? Nada mais do que o aumento da pobreza e da falta de oportunidades, que cairão eventualmente sob o manto do "Dumping Social".

\section{CONSIDERAÇÕES FINAIS}

A época de crise possui consequências acima do alcance dos governos locais, com problemas globais que acabam sendo resolvidos localmente, mas com Estados que se rendem aos fluxos internacionais. O interesse mercadológico suprime, dessa forma, os direitos trabalhistas. Ocorrem reestruturações produtivas que, a pretexto de sanearem crises econômicas, agravam as crises sociais, por ausência de discussão devida das reformas. Nesse sentido, a Reforma Trabalhista é mais uma das legislações que padeceu da falta de aprofundamento sobre as consequências das alterações legais.

Com a aprovação, em 2017, das leis n 13.429 e 13.467, se configurou uma tentativa de salvaguarda econômica, considerada por parcela da doutrina justrabalhista como retrocesso social. Em relação especificamente ao trabalho escravo contemporâneo, modalidade prevista no art. 149 do Código Penal, esse retrocesso se manifesta na maior incidência da prática quando a terceirização é permitida.

33 LOJKINE et al.,1986 apud LOJKINE, Jean. A revolução Informacional. 3. ed. São Paulo: Cortez, 2002. p. 233.

34 GLOBAL SLAVERY INDEX. Website. Disponível em: <https://www.globalslaveryindex.org/>. Acesso em: 12 jun. 2019. 
Com a alteração da essência do Direito do Trabalho pela Reforma Trabalhista, houve também repercussão grande no combate ao trabalho escravo. Optou-se, neste artigo, por examinar a descaracterização do grupo econômico, a desnecessidade de respeito aos princípios do Direito do Trabalho e o tabelamento dos danos extrapatrimoniais, embora se tenha demonstrado a existência de outros pontos que demandam discussão.

A consequência dessas mudanças pode ser indicada como dumping social, que favorece a ocorrência da escravidão contemporânea. Cabe, portanto, estudo mais aprofundado sobre essas relações, aqui explanadas em sobrevoo, observando os voos da Fênix que representa o capitalismo e suas crises cíclicas. Mesmo que aparentem em nada se relacionar à escravidão contemporânea, em realidade são sua causa de ser e dela se utilizam para alçar voos ainda mais altos.

\section{REFERÊNCIAS DAS FONTES CITADAS}

ALMEIDA, Margarida Barreto de. Empresa de grupo e grupo de empresa: desvendando a complexidade subjetiva do empregador. 199 f. Tese (Doutorado em Direito). Faculdade de Direito da UFMG e Università deli Studi di Roma - Tor Vergata, 2017. (no prelo).

ANDRADE, Everaldo Gaspar Lopes de. O Direito do Trabalho na Filosofia e na Teoria Social Crítica. Os Sentidos do trabalho subordinado na cultura e no poder das organizações. São Paulo: LTr, 2014.

BAUMAN, Zygmunt. Mal-Estar na Pós-modernidade. São Paulo: Jorge Zahar, 1998.

BAUMAN, Zygmunt; BORDONI, Carlo. Estado de Crise. Tradução Renato Aguiar. Rio de Janeiro: Jorge Zahar, 2016.

BENOIT, Hector; ANTUNES, Jadir. O problema da crise capitalista em o capital de Marx. Jundiai: Paco Editorial, 2016.

BRASIL. Decreto-lei $n^{\circ}$ 5.452, de $1^{\circ}$ de maio de 1943. Aprova a Consolidação das Leis do Trabalho. Diário Oficial da União, 9 ago. 1943. Disponível em: <http://www.planalto.gov.br/ccivil_03/decreto-lei/Del5452. htm>. Acesso em: 12 jun. 2019.

BRASIL. Lei no 13.429, de 31 de março de 2017. Altera dispositivos da Lei no 6.019, de 3 de janeiro de 1974, que dispõe sobre o trabalho temporário nas empresas urbanas e dá outras providências; e dispõe sobre as relações de trabalho na empresa de prestação de serviços a terceiros. Diário Oficial da União, 31 mar. 2017. Disponível em: <http://www.planalto.gov.br/ccivil_03/_Ato2015-2018/2017/Lei/L13429.htm>. Acesso em: 12 jun. 2019.

BRASIL. Lei n 13.467, de 13 de julho de 2017. Altera a Consolidação das Leis do Trabalho (CLT), aprovada pelo Decreto-Lei no 5.452, de 1 o de maio de 1943, e as Leis nos 6.019, de 3 de janeiro de 1974, 8.036, de 11 de maio de 1990, e 8.212, de 24 de julho de 1991, a fim de adequar a legislação às novas relações de trabalho. Diário Oficial da União, 14 jul. 2017. Disponível em: <http://www.planalto.gov.br/ccivil_03/_ato2015-2018/2017/lei/ L13467.htm>. Acesso em: 12 jun. 2019.

BRASIL. Lei n 6.019, de 3 de janeiro de 1974. Dispõe sobre o Trabalho Temporário nas Empresas Urbanas, e dá outras Providências. Diário Oficial da União, 4 jan. 1974. Disponível em: <http://www.planalto.gov.br/ ccivil_03/leis/L6019.htm>. Acesso em: 12 jun. 2019.

CANOTILHO, José Joaquim Gomes. Direito Constitucional. 6. ed. Coimbra: Almedina, 1993. 
COSENTINO, Carlo Benito. Os trabalhadores do conhecimento e o trabalho imaterial: As novas possibilidades de reinvenção das lutas coletivas. 156 f. Dissertação (Mestrado em Direito). Recife, Programa de Pós-Graduação em Direito da UFPE, 2016. Disponível em: <http://repositorio.ufpe.br/bitstream/handle/123456789/18539/ CARLO\%20BENITO\%20Disserta\%C3\%A7\%C3\%A3o.pdf? sequence=1\&isAllowed=y>. Acesso em: 12 jun. 2019.

COUTINHO, Grijalbo Fernandes. Terceirização: máquina de moer gente trabalhadora. A inexorável relação entre a nova merchandage e a degradação laboral, as mortes e mutilações no trabalho. São Paulo: LTR, 2015.

D'ANGELO, Isabele Bandeira de Moraes; RABÊLO, Rebeka Yasmim Teotônio Pereira. Desvendando a flexibilização no direito do trabalho como solução para a crise econômica brasileira: o que os noticiários não contam. Revista Jurídica Unicuritiba, Curitiba, v. 04, n. 53, p. 275-305, 2018.

DELGADO, Maurício Godinho. Direitos fundamentais na relação de Trabalho. In: SILVA, Alessandro da; SOUTO MAIOR, Jorge Luiz; FELIPPE, Kenarik Boujikian; SEMER, Marcelo (Coord.). Direitos Humanos: essência do Direito do Trabalho. São Paulo: LTr, 2007.

FRAHM, Catarina; VILLATORE, Marco Antônio César. Dumping Social e o Direito do Trabalho. s/d. Disponível em: <www.scribd.com.br>. Acesso em: 12 jun. 2019.

GLOBAL SLAVERY INDEX. Website. Disponível em: <https://www.globalslaveryindex.org/>. Acesso em: 12 jun. 2019.

LOJKINE, Jean. A revolução Informacional. 3. ed. São Paulo: Cortez, 2002.

MARX, Karl; ENGELS, Friedrich. Manifesto do partido comunista. Tradução de Sueli Tomazzini Barros Cassal. Porto Alegre: L\&PM. 2002.

PRAUN, Luci. Reestruturação produtiva, saúde e degradação do trabalho. Campinas: Papel Social, 2016.

SILVA, José Afonso da. Curso de direito constitucional positivo. 23. ed. São Paulo: Malheiros, 2004.

VIANA, Márcio Túlio. O que é a terceirização? In: Blog da Boitempo, $1^{\circ}$ abr. 2015. Disponível em: <http:// blogdaboitempo.com.br/2015/04/01/o-que-e-a-terceirizacao/>. Acesso em: 12 jun. 2019.

VIANA, Márcio Túlio; DELGADO, Gabriela Neves; AMORIM, Helder Santos. Terceirização - aspectos gerais. A última decisão do STF e a Súmula 331 do TST. Novos enfoques. Rev. TST, Brasília, v. 77, n. 1, p. 54-84, jan./mar. 2011. Disponível em: < http://siabi.trt4.jus.br/biblioteca/acervo/Doutrina/artigos/Revista\%20do\%20 Tribunal\%20Superior\%20do\%20Trabalho/2011/n\%201/Terceiriza\%C3\%A7\%C3\%A30\%20-\%20aspectos\%20 gerais\%20A\%20\%C3\%BAltima\%20decis\%C3\%A3o\%20do\%20STF\%20e\%20a\%20S\%C3\%BAmula\%20n\%20 331\%20do\%20TST\%20Novos\%20enfoques.pdf>. Acesso em: 12 jun. 2019.

Recebido em: 26/06/2020

Aprovado em: $23 / 11 / 2020$ 